\title{
What is the Adequate Cuff Volume for Tracheostomy Tube? A Pilot Cadaver Study
}

\author{
Dong Min Kim, MD, Myung Jun Shin, MD, PhD, Sung Dong Kim, MD, PhD, \\ Yong Beom Shin, MD, PhD, Ho Eun Park, MD, Young Mo Kim, MD, Jin A Yoon, MD, PhD
}

Department of Rehabilitation Medicine, Pusan National University School of Medicine-Biomedical Research Institute, Pusan National University Hospital, Busan, Korea

Objective To determine the patterns of tracheostomy cuff pressure changes with various air inflation amounts in different types of tracheostomy tubes to obtain basic data for appropriately managing long-term tracheostomy. Methods We performed tracheostomy on a 46-year-old male cadaver. Three types of tracheostomy tubes (singlecuffed, double-cuffed, and adjustable flange), divided into 8 different subtypes based on internal tube diameters and cuff diameters, were inserted into the cadaver. Air was inflated into the cuff, and starting with $1 \mathrm{~mL}$ air, the cuff pressure was subsequently measured using a manometer.

Results For the $7.5 \mathrm{~mm} / 14 \mathrm{~mm}$ tracheostomy tube, cuff inflation with $3 \mathrm{~mL}$ of air yielded a cuff pressure within the recommended range of $20-30 \mathrm{cmH}_{2} \mathrm{O}$. The $7.5 \mathrm{~mm} / 24 \mathrm{~mm}$ tracheostomy tube showed adequate cuff pressure at 5 $\mathrm{mL}$ of air inflation. Similar values were observed for the $8.0 \mathrm{~mm} / 16 \mathrm{~mm}$ and $8.0 \mathrm{~mm} / 27 \mathrm{~mm}$ tubes. Double-cuffed tracheostomy cuff pressures $(7.5 \mathrm{~mm} / 20 \mathrm{~mm}$ and $8.0 \mathrm{~mm} / 20 \mathrm{~mm}$ tubes $)$ at $3 \mathrm{~mL}$ air inflation had cuff pressures of $18-20 \mathrm{cmH}_{2} \mathrm{O}$ at both the proximal and distal sites. For the adjustable flange tracheostomy tube, cuff pressure at 6 $\mathrm{mL}$ of cuff air inflation was within the recommended range. Maximal cuff pressure was achieved at inflation with almost $14 \mathrm{~mL}$ of air, unlike other tube types.

Conclusion Various types of tracheostomy tubes showed different cuff pressures after inflation. These values might aid in developing guidelines For patients who undergo tracheostomy and are discharged home without cuff pressure manometers, this standard might be helpful to develop guidelines.

Keywords Tracheostomy, Pressure, Tracheomalacia, Respiratory care

Received December 11, 2019; Revised May 15, 2020; Accepted July 31, 2020; Published online September 28, 2020 Corresponding author: Jin A Yoon

Department of Rehabilitation Medicine, Pusan National University School of Medicine-Biomedical Research Institute, Pusan National University Hospital, 179 Gudeok-ro, Seo-gu, Busan 49241, Korea. Tel: +82-51-240-7484, Fax: +82-51-247-7485, E-mail: yjk5289@naver.com

ORCID: Dong Min Kim (https://orcid.org/0000-0001-6994-5430); Myung Jun Shin (https://orcid.org/0000-0003-4010-0383); Sung Dong Kim (https:// orcid.org/0000-0002-8436-5722); Yong Beom Shin (https://orcid.org/0000-0001-5026-1696); Ho Eun Park (https://orcid.org/0000-0002-4254-0596); Young Mo Kim (https://orcid.org/0000-0002-2518-530X); Jin A Yoon (https://orcid.org/0000-0001-5762-0559).

(c) This is an open-access article distributed under the terms of the Creative Commons Attribution Non-Commercial License (http://creativecommons.org/ licenses/by-nc/4.0) which permits unrestricted noncommercial use, distribution, and reproduction in any medium, provided the original work is properly cited. Copyright () 2020 by Korean Academy of Rehabilitation Medicine 


\section{INTRODUCTION}

The critical functions of endotracheal tube cuffs are blocking aspiration of pharyngeal contents into the trachea by sealing the airway and preventing air leakage through the cuff during positive pressure ventilation [1]. High-compliance endotracheal tubes are mainly used for sealing the airway to prevent pulmonary aspiration [2]. Although cuffs need to be loaded with pressures high enough to prevent the loss of tidal volume and aspiration into the trachea, problems caused by excessive cuff pressures also need to be considered [3-7]. The main issues after consistently high cuff pressures are decreased tracheal capillary perfusion, direct tracheal wall injury leading to loss of mucosal cilia, ulceration, bleeding, and even tracheoesophageal fistulas in severe cases $[5,8]$. Nordin [5] reported that when the cuff pressure was higher than $40 \mathrm{cmH}_{2} \mathrm{O}$, the cuff inflation volume transmitted direct injury to the tracheal wall. In addition, Bernhard et al. [9] reported that while a thin-walled cuff with approximately $25 \mathrm{cmH}_{2} \mathrm{O}$ of cuff pressure is adequate in preventing tracheal aspiration, the pressure exerted by the cuff on the tracheal wall may exceed the capillary perfusion pressure when used for a longer time, resulting in ischemic damage. Various strategies have been employed to decrease tracheal injury such as regular cuff deflation, alternating inflation with double cuffs, inflating only during aspiration, and careful inflation. However, these techniques were not effective [10]. Therefore, attempts have been made to obtain a low-pressure, high-volume endotracheal tube cuff for several years. The ideal cuff inflation pressure minimizing the risk of both tracheal wall injury and aspiration has been known to be approximately $20-30 \mathrm{cmH}_{2} \mathrm{O}[5,11]$.
The Korean National Health Insurance provides coverage for portable ventilators for patients with motor neuron diseases and respiratory failure disorders who are incapable of spontaneous breathing. A large number of these patients are released from the hospital with a tracheostomy [12]. When long-term vent care is necessary, simple cuff pressure palpation is not sensitive enough to detect problems [13]. Not many patients possess cuff pressure manometers at home. Therefore, the significance of routine cuff pressure measurement has been emphasized $[14,15]$.

The present pilot study aimed to obtain basic data for the appropriate management of long-term tracheostomy tube application. The pressure changes in several kinds of tracheostomy tubes commonly used in clinical practice were measured and compared according to the level of cuff air inflation. Furthermore, the characteristics of each tracheostomy tube type and its prioritization for use during specific situations were also considered.

\section{MATERIALS AND METHODS}

This study conformed to the provisions of the Declaration of Helsinki. Approval from the Institutional Review Board of our institution was waived since this study did not use human subjects for research.

Tracheostomy was performed in a 46-year-old male cadaver. Three of the most commonly used tracheostomy tubes in clinical practice were then inserted and inflated with air. Cuff pressures from each were subsequently measured.

Tube types included a Portex (Smiths Medical Inc., Plymouth, MN, USA) cuffed tracheostomy tube, a Portex tracheostomy tube with a double cuff, and a Portex ad-

Table 1. Types of tracheostomy tubes

\begin{tabular}{lccc}
\hline \multicolumn{1}{c}{ Tube type } & $\begin{array}{c}\text { Tube subtype } \\
\text { (catalog\#) }\end{array}$ & $\begin{array}{c}\text { Internal tube diameter } \\
\text { (mm) }\end{array}$ & $\begin{array}{c}\text { Resting cuff diameter } \\
\text { (mm) }\end{array}$ \\
\hline Portex cuffed tracheostomy tube & $100 / 510 / 075$ & 7.5 & 14 \\
& $100 / 510 / 080$ & 8.0 & 16 \\
& $100 / 518 / 075$ & 7.5 & 24 \\
\hline Portex tracheostomy tube with double cuff & $100 / 518 / 080$ & 8.0 & 27 \\
& $100 / 512 / 075$ & 7.5 & 20 , double cuff \\
& $100 / 512 / 080$ & 8.0 & 20 , double cuff \\
Portex cuffed adjustable flange tracheostomy tube & $100 / 523 / 070$ & 7.0 & 24 , adjustable \\
& $100 / 523 / 080$ & 8.0 & 30 , adjustable \\
\hline
\end{tabular}


justable neck flange hyperflexion tracheostomy tube with a longer maximal cannula.

Tracheostomy tubes were divided into a total of 8 subtypes, depending on the internal tube and resting (without air inflation) cuff diameters. There were 4 subtypes for single-cuffed tracheostomy tubes, 2 subtypes for double-cuffed tracheostomy tubes, and 2 subtypes for adjustable tracheostomy tubes (Table 1).

Thereafter, air was injected slowly into the cuff of each tracheostomy tube in increments of $1 \mathrm{~mL}$. To measure the pressure, a sufficient time interval was given after each milliliter $(\mathrm{mL})$ of air inflation. Cuff pressure was monitored using a manometer (VBM Medizintechnik GmbH, Sulz am Neckar, Germany) until the cuff pressure exceeded $120 \mathrm{cmH}_{2} \mathrm{O}$. For double-cuffed tracheostomy tubes, both the proximal and distal pressures were measured. Two rehabilitation medicine clinicians measured the pressure three times each. The mean pressure value was then recorded. To ensure equivalent tracheal compliance conditions, pressures were measured by each clinician at 30-minute intervals. In addition, the pressures of different types of tubes were measured on different days.

Since it would be impossible to measure and compare the pressures of 8 types of tracheostomy tubes in a live patient, we reviewed the $7.5 \mathrm{~mm} / 24 \mathrm{~mm}$ cuffed tracheostomy tube cuff pressures and tracheal diameters of 2 male patients from the same age group (Patient A: male, 54 years old; Patient B: male, 63 years old). These representative values were compared to those obtained with the cadaver.

For statistical analyses, the SPSS version 18 software was used to calculate the intra-class correlation coefficients (ICCs).

\section{RESULTS}

On the cadaver, tracheostomy was performed between the second and third tracheal rings [16]. After inserting the tracheostomy tube, the cuff was placed between the fifth and sixth tracheal rings. The inner tracheal diameter at the site of the cuff was $20.5 \mathrm{~cm}$. On chest X-ray, the inner tracheal diameters around the cuff inflation site for the 2 patients were $20.53 \mathrm{~mm}$ and $19.58 \mathrm{~mm}$, respectively.

The pressures showed excellent agreement between raters (ICC $=0.94 ; 95 \%$ confidence interval, 0.87-0.98). A pressure of $20-30 \mathrm{cmH}_{2} \mathrm{O}$, corresponding to the green area on the manometer, was measured at $3 \mathrm{~mL}$ air inflation in the $7.5 \mathrm{~mm} / 14 \mathrm{~mm}$ and $8.0 \mathrm{~mm} / 16 \mathrm{~mm}$ cuffed tracheostomy tubes. The $7.5 \mathrm{~mm} / 24 \mathrm{~mm}$ and $8.0 \mathrm{~mm} / 27$ $\mathrm{mm}$ tube types with bigger diameters maintained optimal pressures at $5 \mathrm{~mL}$. At the same volume of inflation, all 4 types had higher pressures in tubes with smaller diameters.

The pressures in the double-cuffed tracheostomy tubes were within the recommended range in both $7.5 \mathrm{~mm} / 8.0$ $\mathrm{mm}$ tube types at 3-4 $\mathrm{mL}$ air inflation. No significant difference between the proximal and distal cuff pressures of the cadaver or tracheal lesions that could influence the results were observed.

The adjustable tube maintained optimal pressures at 6 $\mathrm{mL}$ and at $6-7 \mathrm{~mL}$ for the $7.0 \mathrm{~mm} / 24 \mathrm{~mm}$ and $8.0 \mathrm{~mm} / 30$ $\mathrm{mm}$ tubes, respectively. It was possible to measure pressures up to $15 \mathrm{~mL}$ inflation on the manometer (Table 2).

The pressures of the $7.5 \mathrm{~mm} / 24 \mathrm{~mm}$ cuffed tracheostomy tubes for both patients were within the recommended range at $5 \mathrm{~mL}$ inflation $\left(23 \mathrm{cmH}_{2} \mathrm{O}\right.$ and $28 \mathrm{cmH}_{2} \mathrm{O}$, respectively). These were identical to the cadaveric values (Fig. 1).

\section{DISCUSSION}

In case of our cadaver, ideal air inflation for Portex cuffed tracheostomy tube and Portex tracheostomy tube with double cuff was 3-5 $\mathrm{mL}$ depending on the size of internal tube diameters and resting cuff diameters. The recommended representative cuff pressure for real patient showed the same result as that of the cadaver study, demonstrating the reliability of our study. For adjustable neck flange tubes, 6-7 mL was the optimal inflation volume.

To compare the characteristics depending on the type of tracheostomy tube and priority of each type of tube at specific situations, we used 3 types of the Portex cuff tracheotomy tube, which is widely used in Korea. The Portex cuff tracheotomy tube is mostly used to prevent aspiration into the trachea regardless of the patient group. It provides mild support to patients who have had a tube insertion for the first time because it is made of heat sensitive polyvinyl chloride, which becomes softer at the body temperature of patients, making it more convenient because of lower stimulation. In addition, a double-cuffed tracheotomy tube is useful for alternative- 


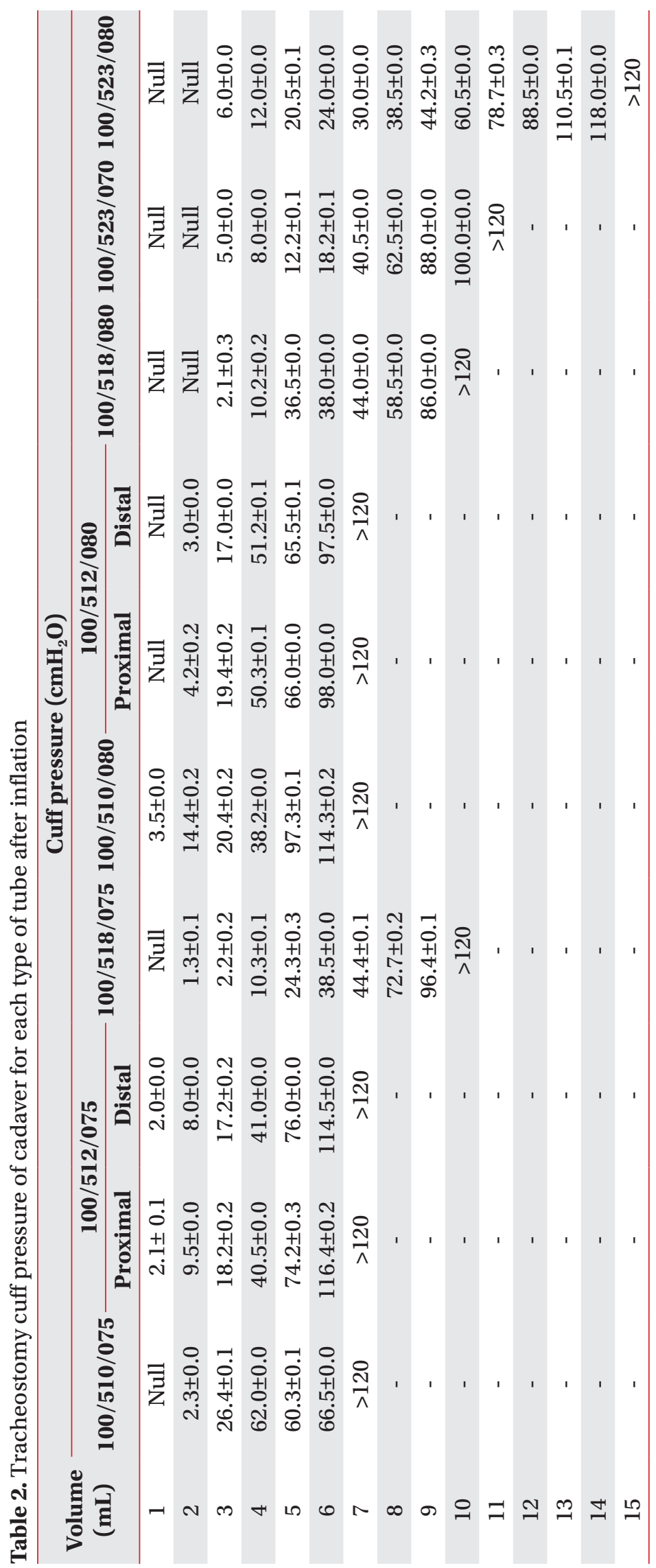




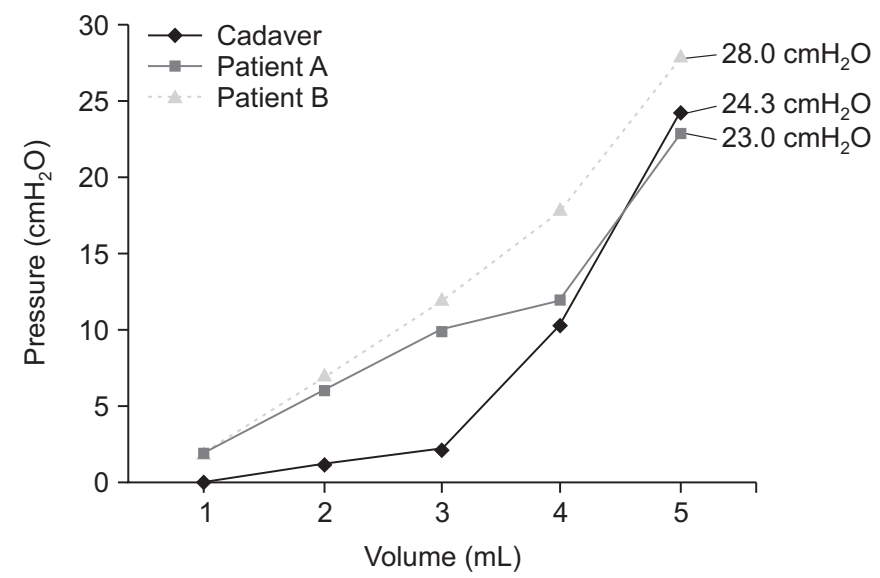

Fig. 1. Equivalent air inflation ( $5 \mathrm{~mL}$ ) for ideal cuff pressure $\left(20-30 \mathrm{cmH}_{2} \mathrm{O}\right)$ in the cadaver and 2 patients with 7.5 $\mathrm{mm} / 24 \mathrm{~mm}$ tube insertion (Portex 100/518/075).

ly shifting the pressure between different regions of the tracheal walls. Adjustable neck flange tubes, which have a characteristic longer maximal cannula including a 15 $\mathrm{mm}$ connector, can be used in patients who have unusual anatomy or pathology, such as glottic edema and obesity [17].

Based on the assumption that the cuff pressure would be different depending on each individual, the present study was performed with a cadaver of a male in his $40 \mathrm{~s}$ with no lesions in the trachea region, and with a standard tracheal lumen diameter, which on average is approximately $19.5 \pm 2.3 \mathrm{~mm}$ in adult males in their 40s [18]. We compared the data with those of 2 male patients of the same age and in the same tracheal lumen diameter group. In addition, the time interval was sufficient to minimize the effect of tracheal tissue transformation after formaldehyde fixation and make equivalent conditions of the trachea compliance. We selected patients who underwent insertion of the most commonly used single-cuff tracheostomy tube. In consideration of ethical concerns, we attempted to minimize tube replacement and air inflation to keep them within the recommended range for each patient. This was to determine whether the increased pressure pattern and optimal inflation volume were consistent with those of the cadaver and control groups. We confirmed that the optimal inflation volume in both the cadaver and control groups was $5 \mathrm{~mL}$ (Fig. 1).

Optimal capacities of air inflation and pressure were identified depending on the subtype of each tracheostomy tube. Tubes with smaller cuff diameters tended to

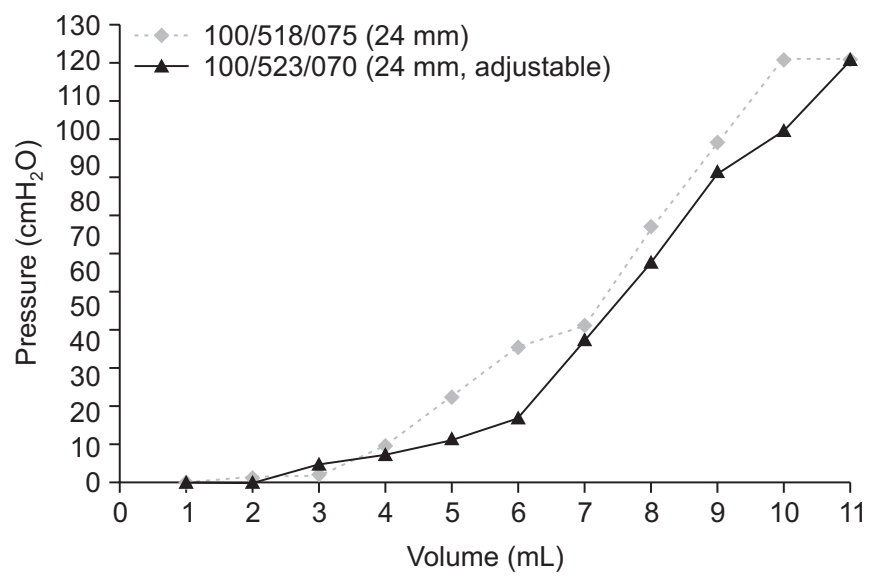

Fig. 2. Lower cuff pressure with equal air inflation in an adjustable tracheostomy tube $(100 / 523 / 070)$ compared to a single-cuffed tracheostomy tube (Portex 100/518/075).

have higher pressures at the same capacity of air inflation than tubes of the same type with bigger diameters. However, it could not be simply concluded that a bigger cuff is more advantageous, because we were unable to determine if a tube with a bigger cuff would have a better sealing effect than a tube with smaller one at the corresponding air inflation. To this end, in cases of real patients, air leakage would have to be checked through mechanical ventilation.

In addition, the present study found no significant difference between proximal and distal cuff pressures of double-cuffed tubes. However, it is thought that alternative ballooning of double-cuffed tubes would be useful for minimizing the degree of damage in cases of tracheal stenosis, tracheomalacia, and focal tracheal lesion due to a long-term tracheostomy [19].

An additional remarkable result was regarding the cuff pressure of the adjustable tubes. It was easily predictable that the tube with the biggest resting cuff diameter $(30 \mathrm{~mm})$ in this tube type would have a higher maximal air inflation capacity within the recommended pressure range than the smaller resting cuff diameter tubes. However, the pressure was lower in adjustable tubes than in single-cuffed tracheostomy tube at the same capacity of inflation compared to single-cuffed tubes with the same resting diameter when injecting the same volume, which is thought to be related with normal tracheal anatomy (Fig. 2). In other words, since it is natural that the diameter and cross-sectional area increase in the portion of the trachea close to the carina, an adjustable tube with 
a longer tracheal portion than that of other tubes is inserted deeper, so that the pressure between the tracheal wall for a broader area and the cuff is measured with an adjustable tube compared to other types, resulting in the above results [20].

Several limitations of the present study should be considered. First, the results from a cadaver cannot be directly applied to patients. If there are insufficient intervals while performing tracheostomy ballooning several times in a cadaver fixed with formaldehyde, inter-rater and intra-rater reliability of pressure measurements could be affected by already stiffened smooth muscle. Therefore, the present study attempted to enhance the reliability of data by measuring at different days and at 30-minute intervals. In addition, this was a preliminary study conducted on a male cadaver in his 40s using 2 patients as controls. To present standardized data, further studies accounting for differences in sex, age, and tracheal diameter are necessary. In our study, considering the possible difference in compliance of the tracheal tissue between the cadaver and the patients, it was meaningful to confirm that the air inflation volume within the optimal pressure was the same (Fig. 1) for both groups. Second, as high volume and low pressure were used in this study, there is a possibility of the cuff inflation volume and pressure increasing owing to the body temperature [21]. Further studies are needed to evaluate the effects of body temperature on changes in pressure pattern. Third, we did not compare the different effects of texture of the cuff membrane. Dullenkopf et al. [22] performed an in vitro study that showed that the ultrathin polyurethane cuff was desirable for high volume and low pressure compared to other types. Since the results were obtained through a cadaver, additional experimental groups would be needed to generalize these values for direct application to patients. However, this study was meaningful to emphasize the importance of routine screenings and necessity for monitoring adequate cuff pressure for longterm tracheostomy state patients.

In conclusion, tracheostomy tubes showed different cuff pressures after inflation characteristics depending on the type of tracheostomy tube. For tracheostomy state patients who are discharged home without cuff pressure manometers, this standard might be helpful to develop guidelines. In addition, double-cuffed tracheostomy using adjustable flange tracheostomy tubes can be recom- mended for some patients requiring more pressure.

\section{CONFLICT OF INTEREST}

No potential conflict of interest relevant to this article was reported.

\section{ACKNOWLEDGMENTS}

This work was supported by clinical research grant from Pusan National University Hospital in 2020.

\section{AUTHOR CONTRIBUTION}

Conceptualization: Kim DM, Yoon JA. Methodology: Kim DM, Yoon JA. Formal analysis: Yoon JA, Shin YB. Funding acquisition: Yoon JA. Project administration: Yoon JA, Shin YB. Visualization: Yoon JA, Kim SD. Writing - original draft: Kim DM, Yoon JA. Writing - review and editing: Kim DM, Yoon JA, Shin MJ, Park HE, Kim YM. Approval of final manuscript: all authors.

\section{REFERENCES}

1. Sengupta P, Sessler DI, Maglinger P, Wells S, Vogt A, Durrani J, et al. Endotracheal tube cuff pressure in three hospitals, and the volume required to produce an appropriate cuff pressure. BMC Anesthesiol 2004;4:8.

2. Braz JR, Navarro LH, Takata IH, Nascimento Junior P. Endotracheal tube cuff pressure: need for precise measurement. Sao Paulo Med J 1999;117:243-7.

3. Stauffer JL, Olson DE, Petty TL. Complications and consequences of endotracheal intubation and tracheotomy: a prospective study of 150 critically ill adult patients. Am J Med 1981;70:65-76.

4. Leigh JM, Maynard JP. Pressure on the tracheal mucosa from cuffed tubes. Br Med J 1979;1:1173-4.

5. Nordin U. The trachea and cuff-induced tracheal injury: an experimental study on causative factors and prevention. Acta Otolaryngol Suppl 1977;345:1-71.

6. Klainer AS, Turndorf $\mathrm{H}, \mathrm{Wu} \mathrm{WH}$, Maewal H, Allender P. Surface alterations due to endotracheal intubation. Am J Med 1975;58:674-83.

7. Shelly WM, Dawson RB, May IA. Cuffed tubes as a cause of tracheal stenosis. J Thorac Cardiovasc Surg 
1969;57:623-7.

8. Bernhard WN, Yost L, Joynes D, Cothalis S, Turndorf H. Intracuff pressures in endotracheal and tracheostomy tubes. Related cuff physical characteristics. Chest 1985;87:720-5.

9. Bernhard WN, Cottrell JE, Sivakumaran C, Patel K, Yost L, Turndorf H. Adjustment of intracuff pressure to prevent aspiration. Anesthesiology 1979;50:363-6.

10. Bryant LR, Trinkle JK, Dubilier L. Reappraisal of tracheal injury from cuffed tracheostomy tubes: experiments in dogs. JAMA 1971;215:625-8.

11. Park YJ, Lee J, Kim SH, Ko SH, Shin MJ, Chang JH, et al. Care status of the ALS patients with long-term use of tracheostomy tube. Ann Rehabil Med 2015;39:96470.

12. Suh MR, Choi WA, Choi YC, Lee JW, Hong JH, Park J, et al. Long-Term outcome of amyotrophic lateral sclerosis in Korean subjects. Ann Rehabil Med 2017;41:1055-64.

13. Fernandez R, Blanch L, Mancebo J, Bonsoms N, Artigas A. Endotracheal tube cuff pressure assessment: pitfalls of finger estimation and need for objective measurement. Crit Care Med 1990;18:1423-6.

14. Dunn CR, Dunn DL, Moser KM. Determinants of tracheal injury by cuffed tracheostomy tubes. Chest
1974;65:128-35.

15. Lewis FR Jr, Schiobohm RM, Thomas AN. Prevention of complications from prolonged tracheal intubation. Am J Surg 1978;135:452-7.

16. Durbin CG Jr. Techniques for performing tracheostomy. Respir Care 2005;50:488-96.

17. Hess DR. Tracheostomy tubes and related appliances. Respir Care 2005;50:497-510.

18. Breatnach E, Abbott GC, Fraser RG. Dimensions of the normal human trachea. AJR Am J Roentgenol 1984;142:903-6.

19. St John RE, Malen JF. Contemporary issues in adult tracheostomy management. Crit Care Nurs Clin North Am 2004;16:413-30.

20. Otoch JP, Minamoto H, Perini M, Carneiro FO, de Almeida Artifon EL. Is there a correlation between right bronchus length and diameter with age? J Thorac Dis 2013;5:306-9.

21. Al-Shaikh B, Stacey SG. Essentials of equipment in anaesthesia, critical care, and peri-operative medicine. Edinburgh, UK: Elsevier; 2018.

22. Dullenkopf A, Gerber A, Weiss M. Fluid leakage past tracheal tube cuffs: evaluation of the new Microcuff endotracheal tube. Intensive Care Med 2003;29:184953. 